\title{
Yürüme döneminde küçük konuşmacılar: Gelişimsel bir bakış
}

\section{Little talkers in toddlerhood: A developmental perspective}

\section{Makale Geçmişi \\ Geliş : 2 Ocak 2020 \\ Düzeltme : 17 Mart 2020 \\ Kabul : 18 Mart 2020}

\section{Makale Türü}

Derleme Makale

\section{Article History}

Received : 2 January 2020

Revised : 17 March 2020

Accepted : 18 March 2020

Article Type

Review Article

\author{
Ayşe Belgin Aksoy ${ }^{1}$, Merve Aksoy ${ }^{2}$
}

Öz: Bu araştırmada, alanyazında yeni yürüyen döneminde dil gelişimine ilişkin kuramsal bilgilerin güncel araștırmalarla birlikte incelenmesinin gerekliliğini ortaya koymak amaçlanmıștır. Yaşamın önemli dönemlerinden biri olan yeni yürüyen dönemi bebeklik ile okul öncesi dönem arasındaki geçiş sürecidir ve bu dönemde dil gelişiminde hızlı bir performans sergilenmektedir. Ses çıarma, ses taklitleri, hece tekrarları ve ilk sözcügün söylenmesi gibi evrensel bir dil edinim dizisi yeni yürüyen döneminde gerçekleșmektedir. Bu çalışmada, güncel ulusal ve uluslararası araștırmalar ıṣığında yeni yürüyen döneminde dil gelişimi ve basamakları, yeni yürüyen döneminde dil gelişimini etkileyen faktörler, dil gelişimini desteklemede neler yapılması gerektiği konuları ele alınmıştır.

Anahtar Kelimeler: Dil gelişimi, Yeni yürüyen çocuk, Çocuk gelişimi

Abstract: In this study, it is aimed to reveal the necessity of analyzing the theoretical information about language development in the toddlerhood in the literature together with current researches. One of the important periods of life, toddlerhood is the transition between infancy and preschool period and there is a rapid performance in language development. A universal series of language acquisition, such as sound extraction, sound imitations, syllable repetitions, and the first word being spoken, take place during toddlerhood. In this study, language development and its steps in toddlerhood, factors affecting language development in toddlerhood, what needs to be done to support the language development are discussed and a review is made in the light of current international and national studies.

Keywords: Language development, Toddlerhood, Child development 


\section{SUMMARY}

\section{Introduction}

A rapid development is performed for all developmental areas in toddlerhood. In language development, a universal series of language acquisition such as making sound, sound imitations, syllable repetitions, and the first word being spoken take place during toddlerhood period (Bredekamp, 2015; Santrock, 2016). Awareness of language skills in the early period is important to support the language development of babies and children correctly and appropriately, as well as to make the developmental follow-up of the child by being aware of the language skills. When the literature is examined, no study has been found that examines language development knowledge in the light of current researches and examines how the literature and the researches support and overlap each other. In this direction, the aim of the study is to reveal the necessity of analyzing the theoretical information about language development in the toddlerhood together with current researches.

\section{Method}

The following steps were followed in the determination of the articles reviewed in the study:

- 15 Database, with intersection of databases that are determined by TÜBİTAK National Metrology Institute based on IHS Standard Database and databases accessible from Gazi University Library (Academic Search Complete, Annual Reviews, BMJ, Cambridge University Press, Cocrane Library, Dynamed, Ebsco, Science direct, Eric, Medline, Oxford Journals Online, Scopus, Taylor\&Francis, Web of Science, Wiley) were determined

- In addition to these databases, Dergipark Academic database has been added as it provides access to various and Turkish sources.

- The scans were conducted in February 2019 with the words "Toddlers language development, Babies language development, Yeniyürüyen dil gelişimi, Bebek dil gelişimi”.

- 42 international and national studies, which were open to access and published between January 2014 and December 2018, were examined.

\section{Results}

\section{Language Development Process in Toddlerhood}

Weitzman and Greenberg (2012) described the early language development process as an explorer from birth to eight months, during which time the baby cries, laughs, makes noises and cannot yet send a message to someone else. Eight months to thirteen months, the communicator, where the baby makes eye contact, 
facial expressions, gestures and voices and gives messages with purpose. Between twelve months and eighteen months, the user of the first word, during this time when the baby decodes the language and uses single words. From eighteen months to twenty-four months, he is unifying, and in this process s/he begins to unite words, and thinks s/he can chat with me now. Between the ages of two and three, he is the founder of early sentences, from two-word sentences to five-word sentences and they have short conversations. Between the ages of three and five, he is the founder of advanced sentences, they form long and complex sentences. In this early stage, language development is affected by environmental and biological factors.

\section{Factors Affecting Language Development in Toddlerhood}

Alhammadi (2017) stated that the majority of the factors affecting language development are environmental and then biological, and finally, some developmental disorders and delays affect language development. Chomsky, on the other hand, asserts that people are biologically equipped to learn languages and in a certain way with the language acquisition theory, which he describes as an innate ability (Trawick Smith, 2017). Language development skills of children of low-income and low-education families are negatively affected (Justice et al., 2019; Muluk, Bayoğlu \& Anlar, 2016; Robets et al., 2018; Ahn \& Yoo, 2016). It has been determined that having an older sibling enables children to have more vocabulary (Bridges \& Hoff, 2014). Preterm labor has also been shown to affect negatively language skills of children in toodlerhood (Lowe et al., 2019; Marchman, Adams, Loi, Fernald and Feldman, 2016; Brosch-Fohraheim, Fuiko, Marschik \& Resch, 2019). In the studies conducted during the toddlerhood, it was found that humanity affects language development in favor of girls (Gudmundsson, 2015; Stangeland, Lundetrae \& Reikeras, 2018).

\section{Supporting Language Development in Toddlerhood}

During infancy, adults should respond with words by speaking to babies who is crying and chirp, so that the baby is encouraged to try out the sounds that will turn into first words and gain experience for speaking. It is necessary to develop and interpret common attention with the child, so that the child learns words faster and early language acquisition is supported (Berk, 2013a). According to Nash, Lowe and Leah (2012), when doing something with the baby, the adult's naming the work, explaining it in words, face-to-face when communicating with the baby, and playing short games with words that are important to support the language development of baby.

\section{Conclusion and Suggestions}

Language development is an important part of the whole development and learning process starting from birth, showing rapid development in the toddlerhood (Santrock, 2016). Many biological and environmental factors affecting language development have been revealed in the literature and researches conducted during the toddlerhood. These factors include brain development, the interaction of individuals in the family with the child, the quality of the interaction, the family's socio-economic level, educational status, having a big sibling, the gender of the child, premature birth and timely birth. However, studies related to language development in this period Turkey is quite limited. In the future, in the toddlerhood that is sensitive to 
language development, there is a need for in-depth researches that will reveal the language development of children more clearly and in line with the literature knowledge. 


\section{GİRIŞ}

Yaşamın en önemli dönemlerinden biri olarak ifade edilen erken çocukluk döneminde yer alan yeni yürüyen dönemi, bebeklikten okul öncesi döneme geçiş sürecini oluşturmaktadır. Yeni yürüyen dönemi Berk'e göre (2013a) 12 ile 24 ay arasındaki çocukları kapsarken, Trawick- Smith’e (2017) göre 18-36 ay arası çocukları kapsamaktadır. Hayata iyi bir başlangıç yapabilmek için bu dönemin de erken çocukluğun diğer dönemleri gibi her yönden nitelikli geçmesi gerekmektedir (Berk, 2013a). Yeni yürüyen döneminde tüm gelişim alanları açısından hızlı bir performans sergilenmektedir. Dil gelişiminde de ses çıkarma, ses taklitleri, hece tekrarları ve ilk sözcüğün söylenmesi gibi evrensel bir dil edinim dizisi yeni yürüyen döneminde gerçekleşmektedir (Bredekamp, 2015; Santrock, 2016).

İstemli sembollerin ve kelimelerin kazanılması, kaydedilmesi ve kurallara uygun bir şekilde kullanılması olarak tanımlanan ve karmaşık bir iletişim sistemi olan dil, yaşamın ilk yıllarında yaşanan bilişsel ve algısal beceriler ile gelişmektedir (Aksoy \& Baran, 2017; Berk, 2013b). İlk y1llarda yaşanan bu gelişimde çocuk "aaaa" gibi çıkardığı seslerden "Ben büyüyünce pilot olmak istiyorum" cümlesine doğru bir değişim ve gelişim gösterir (Weitzman ve Greenberg, 2012). Dil gelişim sürecinde, jest dili, alıcı dil, ifade edici dil, sözel iletişim, sözel olmayan iletişim, monolog, telegrafik konuşma gibi kavramlar yer almaktadır. Jest dili, çocuğun duygu ve düşünceleri açıklamak için kafa sallama, kolları açma, elleri kaldırma gibi bir takım içgüdüsel ve iradeli hareketleri içermektedir (Ünüvar, 2018). Alıc1 dil ise, konuşmaya başlamadan önce bebeğin sözcükleri ve dili anlama becerisidir (Aral ve Doğan Keskin, 2016; Trawick - Smith, 2017). Alıc1 dil kapsamında bebekler konuşulanları anlayarak, sesler ile tepki verme, kendisine söyleneni anlayarak buna uygun davranma şeklinde davranışlar gösterirler (Karaaslan, Beyazıt ve Bütün Ayhan, 2015). İfade edici dilde, çeşitli seslerin üretilmesi ile sözcükler ve cümleler oluşturulmaya başlanır ve dil kurallarına uygun bir şekilde kullanılır. Birey ifade edici dil kapsamında artık kendini anlatabilir. Çocukların ifade edici dilinin gelişmesi için alıcı dilinin gelişmiş olması gerekmektedir (Berk, 2013). Alıcı dil ile ifade edici dil birleşimi kelime haznesini oluşturur (Bredekamp, 2015). Conway ve diğerleri (2017) yaptıkları çalışmada, 24 aylık 200 bebeğin alıcı ve ifade edici dil becerilerinin içselleştirme ve dışsallaştırma davranışları ile ilişkili olup olmadığını incelemişlerdir. Çalışma sonucunda, alıcı dil puanı düşük olan bebeklerin içselleştirme davranışlarının az olduğu, dışsallaştırma davranışlarının ise fazla olduğu görülmüştür. İfade edici dil puanlarının içselleştirme ve dışsallaştırma davranışları ile ilişkisi bulunamamıştır. Sözel iletişim, duygu ve düşünceleri, yaşantıları sözlü şekilde ifade etmedir, ve bu anlamda konuşma, yazı yazma, kitap okuma gibi yöntemler sözel iletişimin içerisinde yer almaktadır. Sözel olmayan iletişimde ise jest ve mimikler, vücut hareketleri, yüz ifadeleri, ses tonu, göz temas1 gibi çeşitli yollar ile iletişim kurulmaktadır. Sözel olmayan iletişim, sözlü iletişim ile birlikte 
kullanılabileceği gibi yalnız başına ayrı bir iletişim biçimi de olabilir (Aksoy \& Baran, 2017). Çocuğun tek başına yüksek sesle düşünüyormuş gibi konuşması ise monologdur. Bu durumda kullanılan dil iletişim amaçlı değildir, fakat çocuğun içinde bulunduğu ortamda haz alarak oynadığını göstermektedir ve doğal bir süreçtir (Yazıc1, 2018). Dilin gelişim sürecinde iki kelime dönemi olarak ifade edilen konuşmalar ise telgraf konuşmalar olarak adlandırılmaktadır. Çocuklar iki kelimeyi yan yana getirerek bir şey anlatmaya çalışmaktadır. Annesinden su istemek için bir çocuğun "anne su" diyerek iki kelimeye bir araya getirmesidir (Berk, 2013b; Yazıc1, 2018).

Dil gelişimine ilişkin yapılan araştırmalarda dilin nasıl öğrenildiğine yönelik kuramsal görüşler yer almaktadır. Bu kuramsal görüşler arasındaki farklılıkların en temelinde çocukların dil gelişimlerinin çevresel ve kalıtımsal özelliklerden ne kadar etkilendiği yer almaktadır. Davranış̧ı kuram, bebeğin çevresinde konuşulanları taklit etmesi ve yetisskinlerin ödüllendirmelerle bebeğin çıkardığ sesleri desteklemelerinin dil kazanımında önemli olduğu üstünde durmaktadır (Karacan, 2000). Skinner (1957), dilin diğer davranışlar gibi edimsel koşullanma ile öğrenildiğini ileri sürmüştür (akt. Berk, 2013a). Davranışçı kuramı destekleyen bir diğer kişi olan Bloom’a göre (1997) çocuğun amacı dili ilk kullanmaya başladığı andan itibaren iletişim kurmak ve aklındaki düşünceleri paylaşmaktır. Bunun yanı sıra çocuk kendisine yardımcı olacak yeni sözcükleri de öğrenir (akt. Bee \& Boyd, 2009). Ayrıca, McCune (1995) ve Shore’a göre (1986) çocuklar, -mış gibi yapma oyunlarını yaşamlarının erken dönemlerinde gösterirler ve çeşitli jestleri sıralı bir şekilde kullanırlar. Böylece konuşmalarında iki ya da üç kelimelik cümleleri de erken yaşlar itibariyle kullanmaya başlarlar (akt. Bee \& Boyd, 2009). Chomsky ve Lenneberg dil gelişimini biyolojik temellere dayandırmışlar ve çevrenin dil gelişimi üzerindeki etkisini de göz ardı etmemişlerdir. Biyolojik (Doğuştancı-Doğacı) kuramda, bebeğin doğuştan getirdiği yeteneklerinden ve dil edinimi bakımından programlanmış olduğundan bahsedilmektedir. Dilin öğrenilmesinde kritik dönemlerin olduğu belirtilmiş, bilişsel gelişimin ve olgunlaşmanın dil gelişiminde en önemli faktörler olduğu vurgulanmıştır (Berk, 2013b; Passer \& Smith, 2008; Vauclair ve Cochet, 2013). Biyolojik kuramcı olan Slobin'e göre (1985) bebeklerin doğuştan çevreye bakınma kuralları gibi çevreyi dinleme kuralları da vardır. Bu kurallar sayesinde bebekler duydukları seslerdeki belirli ses ve hecelere odaklanır, ses ritmine dikkat eder, annesinin dili gibi belirli bir örüntüdeki konuşmayı tercih ederler (akt. Bee ve Boyd, 2009). Sosyal etkileşim kuramında, çocuğun içerisinde bulunduğu, dili öğrendiği sosyal ve kültürel ortamdan etkilendiği, doğrudan taklit ve model almanın dil gelişimi ile ilişkilendirildiği belirtilmektedir (Berk, 2013a; Karacan, 2000). Doğuştan gelen dilsel bilgi işleme kapasitesi bebek beyni donanımında yer alır, bebek bu dilsel girdi ile yola çıkar ve bu bilgiler daha sonra öğrenilen yeni bilgiler ve şemalar ile işlenir. Böylece dili anlama ve yaratma ile ilgili kurallar oluşur (Bee ve Boyd, 2009). Çocukların kullandığ1 kelimeler kendilerine özgü anlamlar içerdiğinden, erken dil becerileri yetişkinlerin 
dilinden farklıdır. Bir kelime geniş anlamda kullanılabilir, kurdukları cümlelerde özne ve yüklem olmayabilir (Weitzman ve Greenberg, 2012; Potter, Fourakis, Morin-Lessard, Byers-Heinlein ve Lew-Williams, 2019). Erken dönemde dil becerilerinin farkında olunması, bebeklerin ve çocukların dil gelişimini doğru ve uygun şekilde desteklemek, ayrıca bebeğin ve çocuğun hangi döneminde dil becerisinin nasıl olacağının farkında olarak çocuğun gelişimsel takibini yapmak adına önemlidir. Alanyazın incelendiğinde erken çocukluk dönemlerinde dil gelişimine ilişkin derleme çalışmaları yer almaktadır (Çiçek, 2002; Dağabakan ve Dağabakan, 2007; Karacan, 2000; Temizyürek, 2008; Yapıc1, 2004), ancak bu çalışmalar arasında alanyazında yer alan yeni yürüyen döneminde dil gelişimi bilgilerini güncel araştırmalar ışı̆̆ında ele alarak inceleyen çalışmaya ulaşılamamıştır. Bu doğrultuda çalışmanın amacı alanyazında yeni yürüyen döneminde dil gelişimine ilişkin kuramsal bilgilerin güncel araştırmalarla birlikte incelenmesinin gerekliliğini ortaya koymaktır. Bu amaç doğrultusunda aşağıdaki sorulara yanıt aranmıştır:

-Yeni yürüyen döneminde dil gelişimi nasıldır?

-Yeni yürüyen döneminde dil gelişimini etkileyen faktörler nelerdir?

-Yeni yürüyen döneminde dil gelişimi nasıl desteklenir?

\section{YÖNTEM}

Bu çalışma, yeni yürüyen döneminde dil gelişimine ilişkin kuramsal bilgiler ile araştırmaların birlikte incelenmesini ortaya koymak amacıyla yapılmış bir derleme çalışmasıdır. Bu kapsamda, TÜBİTAK Ulusal Metroloji Enstitüsü’nün IHS Standart Veri Tabanını baz alarak belirlediği veri tabanları ile Gazi Üniversitesi kütüphanesinden erişime açı veri tabanlarının kesişimi ile 15 veri tabanı (Academic Search Complete, Annual Reviews, BMJ Dergi koleksiyonu, Cambridge University Press, Cocrane Library, Dynamed, Ebsco, Science direct, Eric, Medline, Oxford Journals Online, Scopus, Taylor\&Francis, Web of Science, Wiley) belirlenmiştir. Bu veri tabanlarının yanında çeşitli ve Türkçe kaynaklara erişim sağlaması sebebi ile Dergipark Akademik veri tabanı da eklenmiştir. Taramalar 2019 yılının Şubat ayında "Toddlers language development, Babies language development, Yeniyürüyen dil gelişimi, Bebek dil gelişimi” kelime grupları ile yapılmıştır. Yapılan taramalarda erişime açık, son beş yılı kapsayan Ocak 2014 - Aralık 2018 tarihleri arasında yayınlanmış, özel eğitim alanı dışında kalan 42 uluslararası ve ulusal çalışma (Ek 1) incelenmiştir. İncelenen 42 çalş̧manın, \% 19'una giriş ve yeni yürüyen dil gelişim sürecinde, \%62'sine dil gelişimini etkileyen faktörler, \% 19'una dil gelişimini destekleme bölümünde yer verilmiştir. Bu çalışmalar Ek 1'de sunulduğundan kaynakça bölümünde yinelenmemiştir. 


\section{BULGULAR}

\section{Yeni Yürüyen Döneminde Dil Gelişim Süreci}

Doğum ile birlikte konuşma davranışının bazı yönleri için hazır olan bebekler, göz kontağı ile iletişim kurarlar, uzağa bakarak iletişimi bitirirler. Üç ile dördüncü aylarda yetişkin ile aynı yöne bakmayı ögrenirler ve on ile on birinci ayda bu durum artarak devam eder. Bakım veren ve bebeğin aynı olaya ya da nesneye yöneldiği durumlar ise ortak dikkat olarak tanımlanır. Bakım veren kişinin bu olay ya da nesneyi adlandırması erken dil gelişimine katkı sağlar. Ortak dikkat sürecine katılan bebeklerin dikkatinin daha uzun olduğu, dili daha çok kavradıkları, anlamlı kelimeleri ve jestleri erken ürettikleri, iki yaşına doğru daha hızlı kelime gelişimi gösterdikleri görülmüştür (Berk, 2013a; Weitzman ve Greenberg, 2012). Bebekler henüz ilk kelimelerini söylemeden önce, çevrelerinde konuşulan dili dikkatli bir şekilde dinler, anlar, konuşmaya ilişkin sesler çıkarır ve ilerleme gösterirler (Berk, 2013a). İlk birkaç ayda harflerin seslerine dikkat eder ve aralarındaki farkı kavrarlar. Birkaç ay daha sonra ise hece ve kelimeleri net bir şekilde ayırt edebilir, konuşan kişinin ağız hareketleri ile çıkan seslerin birbiri ile uyumlu olduğunu fark ederler (Bee ve Boyd, 2009; Cavalheiro, Lamônica, Vasconsellos Hage ve Maximino, 2019). Psikodilbilimciler, bebeklik ve yeni yürüyen döneminde dil gelişim sürecini alıcı iletişim ve üretken iletişim olarak sınıflandırmıştır. Alıcı iletişimde, bebeklerin konuşmadan çok daha önce dili anlamaya başladıkları, doğduklarında dili diğer seslerden ayırt edebilmeleri anlamına gelen konuşma alg1sı ile doğdukları bilinmektedir (Trawick - Smith, 2017). Jusczyk ve Hohne (1997), sekiz aylık bebekler ile yaptıkları çalışmada bebeklere çok alışık olmadıkları piton, guguk kuşu gibi kelimelerin yer aldığı hikayeler dinletmişlerdir. İki hafta sonra bebekler, hikayede duydukları yeni kelimelerin yer aldığı bir liste ve hiç duymadıkları kelimelerin yer aldığı ikinci bir liste ile test edilmiştir. Bebeklerin hikayede duydukları kelimelerin yer aldığı listeyi daha uzun süre dinledikleri ortaya çıkmıştır (akt. Santrock, 2016). Bebekler ve yeni yürüyenlerle konuşulmasını, bazı yetişkinler bebekler karşılık vermediği için anlamsız olarak düşünürler. Ancak hayatın ilk anından itibaren bebekler iletişim kurmaya çalıştıklarından yetişkinin bebek ile konuşması önemlidir. Yetişkinler bebekler ile konuşurken birbirleri ile konuştuklarından daha farklı konuşurlar ve ses tonları daha yüksektir. Bu ses tonu ile konuşma bebek dili olarak adlandırılır ve bebekler bu dilden hoşlanırlar (Bredekamp, 2015). Bebeklerin yetişkinleri dinlediği ve konuşmaya benzer sesler çıkardığı bu dönemde, yetişkinler bebeklere yardım etmede zorlansalar bile bu sürece duyarlı olmalıdır (Berk, 2013b).

Bir yaşın ikinci yarısında ise bebekler, kelimelerin ne anlama geldiğini anlarlar ve kelimeleri bir elektrik süpürgesi gibi çekerek hızlı bir şekilde öğrenirler. Bebeklerin önce algısal becerileri gelişir 
ardından ses çıkarma becerileri gelişir (Bee ve Boyd, 2009). Büyümeyle birlikte bebekler, bazı sesler çıkarıp jestler ile iletişim kurarlar. Jestlerin yanına kelimeler eklenince sözel mesajları zenginleşir. Kelime ve jest birlikteliğinden sonra ise jestler giderek azalır ve yerini sadece kelimelere bırakır (Berk, 2013b). Yaşamın ilk aylarında cıvıldama başlar ve "ooo" gibi sesli harfler çıkarılır. Altı ay civarında başlayan agulama/ babıldama döneminde ise cıvıldamaya sessiz harflerde eklenerek bebekler "babababa, nananana" gibi tekrar eden sesler çıkarırlar. Bu sesler ilk çıkarılmaya başladığında hepsi duydukları dilin tonlama örüntüsünde olmasa da on ay civarında ses repertuarı sadece dinledikleri seslerden oluşan bir grup haline gelir. Bates (1987) bu dönemi sözcüklerden önce ses tonunu öğrenme olarak adlandırmıştır (Bee ve Boyd, 2009; Berk, 2013b; McAfee ve Leong, 2011; Passer ve Smith, 2008; Santrock, 2016; Trawick- Smith, 2017).

Bebekler kelimelerin anlamlarını söylemeye başlamadan önce bilirler. Beş aylık bebekler kendi isimleri söylendiğinde ayırt edebilirler. 9 ile 10 aylık bebekler basit talimatları anlar, bu dönemde bebek artık iletişimi anlıyor ve dünya ile iletişime geçmeyi tasarlıyor gibidir. 8 ile 18 aylar arasında ilk kelimeler söylenmeye başlar (Bee ve Boyd, 2009). İlk kelimeler söylendiğinde bazen çocuklar bu kelimeleri çok sınırlı kullanırlar. Örneğin ayı kelimesini sadece oyuncak ayısı için kullanabilir. Bu durum kapsam darlı̆g hatası olarak isimlendirilir. Tam tersi bir durumda ise bir çocuk araba kelimesini otomobil, tren, kamyon gibi tüm taşıtların yerine kullanabilir. Bu durum ise kapsam genişliği hatasıdır (Berk, 2013b). Bir yaşını geçen bebekler ortalama olarak 50 kelimeyi anlar ve bir buçuk yaşına kadar anladığı kelimeleri söyleyemeyebilirler. Söylenen ilk kelimeler genellikle bebeğin çevresindeki önemli kişilerin, tanıdığı hayvanların, oyuncaklarının, kitaplarında resmi yer alan nesnelerin, yiyeceklerin, vücudundaki organların, üzerine giydiği kıyafetlerin, evdeki eşyaların, selamlama sözcüklerinin isimleridir. Bir buçuk yaşında ortalama 50 kelime konuşan bir çocuk iki yaşına geldiğinde konuştuğu kelime sayısı 200-300'e ulaşmaktadır (Bee ve Boyd, 2009; Berk, 2013b; Santrock, 2016; Trawick- Smith, 2017). Lany (2018) tarafından, 17 ve 30 aylık çocuklar ile yapılan çalışmada, 17 aylık çocuklarda sözcüksel işlem etkinliği iyi olanların kelime öğrenme becerilerinin iyi olduğu, 30 aylık çocuklarda ise sözcüksel işlem etkinliğine bakmaksızın iyi düzeyde yeni kelimeler öğrendikleri görülmüştür.

18 ile 24 ay arasında ise iki kelimeyi birleştirerek ilk cümleler kurulmaya başlanır. Bu iki kelimelik kısa ve öz sözcüklerin yer aldığ1 ve dilbilgisel işaretlerin olmadığ1 cümleler telgraf konuşma olarak isimlendirilir. İki sözcüklü konuşmalar, tanımlama (kediye bak), yer belirleme (bardak orada), tekrarlama (çok süt), olumsuzluk (köpek değil), sahiplik (benim arabam), niteleme (büyük kitap), eylemi yapan kişi (baba yürü), eylem - doğrudan nesne (sana vur), eylem-dolaylı nesne (anneye ver), eylem-aracı (kes bıçak), soru (kalem nerede) şeklinde anlam zenginliğine sahiptir. (Berk, 2013b; 
Santrock, 2016; Trawick- Smith, 2017). Yeni yürüyen çocukların bir kelimeyi tanıyı isimlendirdiğinde gerçekte kelimeye ilişkin ne bildiğini öğrenmeyi amaçlayan bir çalışmada, çocuklara tipik (olağan) renklerle ilişkili nesne çiftleri gösterilmiştir. Bazı denemelerde nesneler tipik olarak renklendirilmiş (örneğin, benek desenli inek ve pembe domuz); renklerin değiştirildiği diğer denemelerde ise renkler tam tersi şekilde değiştirilmiştir (örneğin, pembe inek ve benek desenli domuz). Her denemede, küçük çocuklar hedef bir nesne bulmaya yönlendirilmiştir. Çalışma sonucunda, tipik renkli çiftlerde, değiştirilmiş renkleri olan çiftlere göre daha başarılı olmuşlardır ve daha doğru yanıtlar vermişlerdir (Perry ve Saffran, 2017). Yeni yürüyenlerin içinde bulundukları yaş aralığ1 arttıkça fiil kullanımından daha karmaşık kullanımlara (sıfat, soru kelimeleri, zaman ifadeleri, bağlaçlar, yardımcı fiiller, yer bildiren ifadeler) geçtikleri görülmüştür (Bleses, Vach ve Dale, 2018).

Weitzman ve Greenberg (2012), erken dönemdeki dil gelişim sürecini, doğumdan sekiz aylık sürece kadar keşifçi olarak tanımlamıştır, bu süreçte bebek ağlar, güler, ses çıkarır ne istediğini anlatmak için henüz başka birine mesaj gönderemez. Sekiz aydan on üç aya kadar iletişimcidir, burada bebek göz kontağ1 kurar, yüz ifadeleri, jestleri ve çıkardığ1 sesler ile ben seninle konuşuyorum der ve amac1 olan mesajlar verir. On iki ay ile on sekiz ay arasında ise ilk kelimeler kullanıcısıdır, bu süreçte bebek dilin kodunu çözmüştür ve tek kelimeler kullanır. On sekiz aydan yirmi dört aya kadar ise birleştiricidir, bu süreçte kelimeleri birleştirmeye başlar, artık kelimeleri birleştiriyorum hadi benimle sohbet et diye düşünür. İki ile üç yaş arasında ise erken cümleler kurucusudur, iki kelimelik cümlelerden beş kelimelik cümlelere çıkarlar ve kısa sohbetler kurarlar. Üç ile beş yaş arasında ise ileri cümle kurucusudur, uzun ve karmaşık cümleler kurarlar. Ben artık konuşmayı öğrendim yeni şeyler öğrenme zamanı diye düşünürler. Erken dönemdeki tüm bu süreçte dil gelişimi çevresel ve biyolojik etkenlerden etkilenmektedir.

\section{Yeni Yürüyen Döneminde Dil Gelişimini Etkileyen Faktörler}

Alhammadi (2017), dil gelişimini etkileyen etkenlerin büyük çoğunluğunun çevresel olduğunu belirtirken, biyolojik etkenlerin, bir takım gelişimsel bozuklukların ve gecikmelerin de dil gelişimini etkilediğini belirtmiştir. Dili konuşma ve anlama becerisi hem biyolojik etkenlerden hem de çevresel etkenlerden etkilenmektedir. Biyolojik olarak, beyni hasar görmüş kişiler ile gerçekleştirilen çalışmalarda elde edilen bulgulara göre, beynin sol frontal bölgesinde yer alan Broca bölgesi sözcük çıkarmayı sağlamakta iken, beynin sol yarıküre bölgesinde yer alan Wernicke bölgesi ise dili anlamay1 sağlar (Santrock, 2016). Bu alanlarda oluşan hasar dil kaybına ve engele sebep olmaktadır. Plastik, naylon, polyester ve PVC gibi maddelerin üretilmesinde etkin rol oynayan Bisfenol (BPA) maddesine maruz kalan çocuklanın dil gelişimlerinin incelendiği bir araştırmada, zararlı maddenin 
çocukların beyin gelişimini etkilediği ve anne karnında bu maddeye maruz kalan 21 aylık çocukların düşük kelime hazinesine sahip oldukları görülmüsstür (Jensen ve diğerleri, 2019). Dil gelişimi için duyarlı dönem ise, beynin anadil ile ilgili sinaptik bağlantılarının henüz tamamlanmadığı ve çocukların anadillerine egemenliklerinin artmadığı dolayısıyla dile daha duyarlı oldukları, dile ilişkin her şeyi kaydettikleri erken dönemlerdir (Berk, 2013b). Duyarlı dönemde olan, 23 ve 36 aylık aborjin çocuklara verilen dört aylık dil eğitim programının etkisinin incelendiği bir araştırmada, programa katılan çocukların alıcı ve ifade dil becerileri ile ortak dikkatlerinin arttığı (Brookes ve Tayler, 2016), benzer şekilde koruyucu bakım altında olan ve risk altında olduğu düşünülen 24 ile 36 ay arasındaki çocuklara uygulanan erken müdahale programının ardından çocukların dil becerilerinin arttığ1 bulunmuştur (Raby, Freedman, Yarger, Lind ve Dozier, 2019). Yeni yürüyen döneminde normal konuşma gelişimine ve geç konuşma gelişimine sahip çocuklar ile yapılan çalışmalarda, 21 ve 25 aylık 11 geç konuşan, 11 normal konuşma gelişimine sahip yeni yürüyenin kelime öğrenme görevinde aralarında fark olup olmadığını incelemiştir. Yapılan on kelime öğrenme seansının sonunda normal konuşma gelişimine sahip yeni yürüyenler ortalama on bir kelime öğrenirken, geç konuşanların ortalama dört kelime öğrendikleri görülmüştür (Montemarano, 2015). 21 ile 24 aylık 38 yeni yürüyenin alt1 ve sekiz aylık aralıklar ile üç kez değerlendirildiği bir çalışma (Rujas, Casla, Mariscal, Villasoner ve Sanz, 2018) sonucunda ise geç konuşan çocukların dil becerileri tipik konuşma gelişimine sahip çocuklara göre başlangıçta daha gerideyken, ilerleyen ölçümlerde çocuklar büyüdükçe bu farkın azaldığı bulunmuştur.

Chomsky ise doğuştan gelen bir yetenek olarak ifade ettiği dil edinim aracı (DEA) ile insanların belirli bir zamanda ve belirli bir yol ile dil öğrenmeye biyolojik olarak donanımlı olduğunu ileri sürer (Trawick Smith, 2017). Ancak dil edinim aracı olsa da bunun tüm dil gelişimini açıllamayacağ1 düşünülür. Bu durumda Skinner, dilin çevrenin etkisi ve pekiştirme ile edinilen tepkilerden oluştuğunu öne sürmüştür (Berk, 2013b). Örneğin, bir bebek ba-ba dediğinde babasının onu kucağına alması, ona gülümsemesi bebek için bir ödüldür. Böylece bebek daha çok baba demektedir. Hsu, Hadley ve Rıspoli (2017) yaptıkları araştırmada 20 yeni yürüyen ile çalışmışlardır. Bebekler 21, 24, 27, 30, 33 ve 36 aylık olduklarında evlerinde anneleri ile oyunları video kaydına alınarak kelimeleri ve cümleleri değerlendirilmiştir. Araştırma sonucunda kız ve erkek çocuklar arasında fark bulunamazken, ebeveynleri daha fazla dilsel uyaran sağlayanların fiil bilgilerinin daha iyi olduğu, daha konuşkan oldukları ve daha fazla kelime bildikleri görülmüştür. 8 ile 24 aylık çocuklar ve ebeveynleri ile yapılan bir diğer araştırmada, karşılaştırmalı öğretme yöntemi kullanıldığında çocukların öğretilmek istenen fiili öğrenmelerinin kolaylaştığı görülmüştür (Schwarz, Kleeck, Maguire ve Abdi, 2017). 
Düşük gelirli aileler ile yapılan çalışmalarda, 20 ile 25 aylık çocukların erken dil becerileri incelenmiş ve düşük gelirin bakım verenin stres ve depresyon seviyesini arttırdığı, bu durumunda dil gelişimini olumsuz etkilediği görülmüștür (Justice ve diğerleri, 2018). Benzer şekilde, Muluk, Bayoğlu ve Anlar (2016), anne ve babasının eğitim düzeyi yüksek olan çocukların düşük olan çocuklara göre, sosyoekonomik olarak daha üst yerleşim yerlerinde yaşayan çocukların daha alt düzey yerleşim alanında yaşayanlara göre dil becerilerinin daha yüksek olduğunu saptamışlardır. Ebeveynlerinin yaşı daha büyük olan, daha iyi büyük kas gelişimine ve sosyal gelişime sahip 12 aylık bebeklerin de dil gelişimlerinin daha ileri olduğu görülmüştür. Hart ve Risley’in (1995) çalışmasında ise farklı sosyo ekonomik düzeydeki ailelerin çocukları ile konuşmaları bebeklikten üç yaşına kadar video ile kaydedilmiştir. Ebeveynleri devlet yardımı alan ailelerin çocukları üç milyon kelime ile karşılaşırken, ebeveynleri iyi bir kariyer sahibi olanlar ise on bir milyonun üzerinde kelime ile karşılaşmışlardır (akt. Bredekamp, 2015). İki yaş sendromu görülen yeni yürüyenlerde ise, direnç ve öfke durumunun dil edinimini özellikle kızlarda ve düşük sosyo ekonomik seviyedeki yürümeye başlayan çocukları olumsuz etkilediği bulunmuştur (Robets ve diğerleri, 2018). Kore'de 2078 ailenin yeni yürüyen dönemindeki çocuğu ile yapılan bir diğer çalışmada, anne eğitim düzeyi ve sosyo-ekonomik düzey azaldıkça çocukların ifade edici kelime becerilerinin azaldığ1 görülmüştür (Ahn ve Yoo, 2016). Umek, Peklaj ve Socan (2017), yaptıkları çalışmada, ebeveyn eğitim durumunun, erken dönemde kullanılan kelimelerin ve paylaşımlı kitap okuma sıklığının Slovence konuşan 51 çocuğun kelime ve gramer bilgisine etkisini incelemişlerdir. Araştırma çocuklar 16 aylıkken başlamış ve 31 aylık olana dek sürmüştür, 15 aylık zaman aralığında altı kez değerlendirme yapılmıştır. Çocukların yaşı arttıkça kullandıkları kelime sayısı artmış, ebeveyn eğitim durumunun çocukların kelime ve gramer bilgisine her üç ölçümde de bir etkisinin olmadığı, paylaşımlı kitap okuma sıklığının kelime ve gramer becerileri ile pozitif ilişkili olduğu görülmüştür. Yaşamın ilk 3 yılında ebeveynin çocuğa cevap veren iletişiminin çocuğun ilerideki dil becerileri ile pozitif bir şekilde ilişkili olduğu ve kelime öğrenimini kolaylaştırdığı bulunmuştur (Dave, Mastergeorge ve Olswang, 2018). Gebelik sürecinde strese maruz kalan annelerin 30 aylık çocuklarının dil ve kelime öğrenme becerilerinin incelendiği bir çalışmada ise, 30 aylık yeni yürüyenlerin bilişsel ve dil becerileri ile anne stresi ilişkili olmamasına rağmen, düşük stresli annelerin çocuklarının kelime öğrenme becerilerinin daha yüksek düzeyde olduğu görülmüsstür (Austin ve diğerleri, 2017). Ailesinde kendinden büyük kardeşi olan ve iki dilli ailede yetişen çocukların dil becerilerinin incelendiği bir araştırmada, doğduğundan itibaren İngilizce ve İspanyolca'ya maruz kalan çocuklardan büyük kardeşe sahip olanların dil becerilerinin ve kelime haznelerinin daha iyi olduğu, her iki dili de daha çok konuştukları görülmüștür (Bridges ve Hoff, 2014). 
Dil gelişimi ve erken doğum ile ilgili yapılan çalışmalara bakıldığında, 22 ile 26 haftalık doğan ve 401-1000 gram arasında doğum ağırlı̆̆ı olan 1074 bebeğin iki yaşına geldiklerinde bilişsel ve dil becerileri ile davranış problemleri incelenmiş, erkek bebeklerin dil becerilerinin kızlara göre daha düşük olduğu ve bebeklerde görülen davranış problemlerinin yetersiz dil becerileri ile ilişkili olduğu sonucuna ulaşılmıştır (Lowe ve diğerleri, 2019). Erken doğan yeni yürüyenler ile yapılan çalışmalarda, 30 prematüre bebeğin 18 aylık ve 36 aylık olduklarındaki alıcı dil becerileri incelenmiş, alıcı dil becerileri 18 aylıkken yüksek olan çocukların 36 aylıkken de alıcı dil becerilerinin yüksek düzeyde olduğu (Marchman, Adams, Loi, Fernald ve Feldman, 2016), prematüre doğan bebeklerin 36 ve 41 aylık olduklarındaki ifade edici kelime bilgilerinin incelendiği bir diğer araştırmada ise, erken doğan bebeklerin normal zamanda doğan bebeklere göre ifade edici kelime bilgilerinin daha düşük düzeyde olduğu bulunmuştur (Brosch-Fohraheim, Fuiko, Marschik ve Resch, 2019). Zamanında doğan ve erken doğan 97 yeni yürüyenin dil becerilerinin incelendiği bir başka araştırmada ise, bebekler 18 aylık olduklarında, zamanında doğanların erken doğanlara göre daha fazla kelime bildikleri ve dil puanlarının daha yüksek olduğu görülmüştür. Ayrıca bakım verenin kendisi ile daha çok konuşulan hem zamanında doğan hem erken doğan bebeklerin dil becerilerinin daha fazla geliştiği görülmüştür (Adams vd., 2018). Bakım veren ile çocuk arasındaki oyun etkileşiminin kalitesinin incelendiği bir çalışmada, erken doğan ve normal süresinde doğan çocukların 22 aylık olduklarındaki oyun etkileşimleri ile 18. ve 36. aylarda sahip oldukları dil becerileri değerlendirilmiştir. Erken doğan bebeklerin bakım vereni ile daha güven verici bir etkileşimde bulundukları, bakım vereni ile daha etkileşimli iletişim kuran çocukların 36 aylıkken daha fazla kelime öğrendikleri görülmüştür (Loi vd., 2017).

Dil gelişimi ve cinsiyet ile ilgili Norveç'te erken çocukluk eğitim ve bakım merkezlerinde yapılan bir araştırmada 33 aylık 1005 çocuk ile çalışılmıştır. Çalışma sonucunda kızlar hem alıcı dil hem ifade edici dilde, dil etkinliklerine katılımda ve kelime bilgisinde erkeklere göre daha iyi performans göstermişlerdir (Stangeland, Lundetrae ve Reikeras, 2018). Boylamsal olarak planlanan bir diğer çalışmada, çocuklar 18 ve 30 aylık olduklarında gelişimsel dönem ve cinsiyetlerine göre dil becerilerinde değerlendirilmiştir. 30 aylık olan ve iki yaş sendromu yaşayan, öfkesi fazla olan erkek çocuklarda annelerin hassasiyetinin daha düşük olduğu, dil becerilerinin de daha düşük olduğu görülmüştür. 18 aylık iken çocukların öfke seviyelerinin ve anne hassasiyetinin ifade edici dil becerilerini aç1klamada cinsiyete göre bir farkl1l1k göstermediği görülmüş̧ür (Nozadi vd., 2014). Yeni yürüyenlerde dil gelişiminin incelendiği İzlanda'da yapılan bir diğer araştırmada ise, cinsiyetin dil gelişimini kızların lehine olacak şekilde etkilediği görülmüştür (Gudmundsson, 2015). 
Newman, Morini, Kozlovsky ve Panza (2018) yaptıkları çalışmada, aksanın dil edinimi üzerindeki etkisine bakmışlardır. 32 aylık çocuklar ile yürütülen çalışmada aksanlı söylenen harfi içermeyen kelime-nesne eşleşmesi verildiğinde çocuklar da sesleri doğru bir şekilde çıkarmış ve aynı kelimeleri başkalarından duyduklarında tanımışlardır. Ancak aksanlı söylenen harfleri içeren kelime çifti verildiğinde ve çocuk bu kelimeleri duyduğunda yeni kelime zannetmiştir. Yeni yürüyenlerin dil becerilerini aksanlı bir şekilde konuşan kişilerden daha zor öğrendikleri bulunmuştur. Yeni yürüyenlere yabanc1 dil öğretiminin incelendiği bir çalışmada, öğretmenlerin öğretim yöntemleri incelenmiş, dil öğretiminde fiziksel tepki (jestler, hareketler) ve doğal yaklaşım (hazır olana kadar çocuğu zorlamama, müzik, resim, video gibi materyaller kullanma) yöntemlerinin etkili olduğu ve yeni kelime öğretimini kolaylaştırdığı görüşmüştür (Yusuf, Asyik, Yusuf ve Rusdi, 2017). Kelime öğrenimini araştıran bir diğer çalışmada Zimmerman, Christakis ve Meltzof (2007), bebeklerin televizyon ve çeşitli videolar izledikleri her bir saatte izlemeyen bebeklere göre altı ile sekiz kelime daha az öğrendiklerini bulmuşlardır.

\section{Yeni Yürüyen Döneminde Dil Gelişimini Destekleme}

Bebeklik döneminde başlayan agulama ve cıvıldamaya yetişkinler konuşarak kelimeler ile cevap vermelidir. Böylece bebek ilk kelimelere dönüşecek seslerini denemek için cesaretlenir ve konuşma için deneyim kazanır. Çocuk ile ortak dikkat geliştirme ve yorumlama yoluyla çocuk daha hızlı kelime öğrenir ve erken dil kazanımı desteklenir (Berk, 2013a). Dil gecikmeleri yaşayan 18 ile 24 aylık yeni yürüyenler ile yapılan bir araştırmada ise bu çocukların alıcı ve ifade edici dile bağlı olarak bir takım sosyal, duygusal ve davranışsal problemler yaşadıkları görülmüştür (Hawa ve Spanoudis, 2014; Thurm vd., 2018). Bu sebeple yeni yürüyenlerin dil becerilerini desteklemek oluşabilecek sosyal, duygusal ve davranışsal olumsuz durumları önlemek adına önemlidir.

Aileler ve yeni yürüyenler birlikte hikayeler okumalı, farklı yazılı materyallere bakarak zaman geçirmelidir. Bebeklikten itibaren yazılı uyaranlara maruz kalındığında, bebekler ve yeni yürüyenler de bir kitabın nasıl tutulacağını, sayfaların nasıl ve hangi yöne çevrileceğini, okumanın belirli bir tonda ve hızda yapıldığını öğrenirler. Bunlar erken dönem okuma becerilerini geliştirir ve birlikte geçirilen bu sürede çocuk okumanın önemli ve ilginç bir uğraş olduğunu öğrenir (Berk, 2013b; Trawick- Smith, 2017). Manz ve diğerleri (2017), oluşturdukları kitap paylaşma müdahale grubu aracılığıla ekonomik olarak dezavantajı bölgedeki aileler ile çeşitli okuma stratejileri paylaşmışlardır. Ailelerin okuma stratejileri gelişmiş, etkili kitap okumayı öğrenmişler ve çocukları ile bu stratejileri uyguladıklarında çocukların dili anlama, konuşma becerileri ve kelime bilgileri artarak öncekinden daha üst düzey duruma gelmiştir. Kitap okuma ve kitaplardaki resimler 
hakkında konuşmak, dilin her yönü için bebeğe ve çocuğa deneyim sağlar. Ayrıca bu kitap okuma süreçleri Vygotsky'nin (1978) aşamalı destekleme terimini karşlamaktadır. Yetişkinler başta destek sunarlar ve çocuk öğrendikçe kontrolü çocuğa bırakırlar. Bebeklik döneminde kendisine kitap okunan bebeklerin agulamalarının farklı olduğu düşünülmüş ve bu agulamalara kitap agulaması denilmiştir (Trawick - Smith, 2017). İki ile üç yaşlarındaki 15 çocuk ile yapılan bir araştırmada, yedi ay boyunca çocukların devam ettiği eğitim kurumu hikâye zamanı ile öğle yemeği arasındaki kitaplarla etkileşimde bulunulan geçiş zamanında gözlemlenmiştir. Yapılandırılmamış ortamda akranları ile kitap okuma etkileşimleri yaşayan çocukların erken okuma yazma becerileri geliştirdikleri, tıpkı büyük çocuklardaki gibi meraklarını çekecek ve ilgileri doğrultusunda kitapları okumak istedikleri bulunmuştur (Lee, 2017). Kitap okumanın yanında bebeklerin ve çocukların iyi birer hikâye anlatıcısı olmaları da dil gelişiminde önemlidir. Bunun için, yetişkinler çocuk hikayesini anlatırken dinlediğini belli etmeli, anlattıklarının doğruluğunu kabul etmeli, üzerine eklemeler yapabileceği bilgiler vermeli, hikâye ile ilgili özel sorular sormalı ve çocuğun hikâyeyi anlatmasını sürdürmesine yardımcı olmalıdır (Weitzman ve Greenberg, 2012). Yeni yürüyen çocuklarla olan günlük ve anlamlı dil etkileşimleri ile çocuklar zihinsel, duygusal olarak gelişir ve derinleşen dil tecrübeleri ortaya çıkar. Zengin konuşmalar, çocukların gelişimlerine katkı sağlar; sofistike ve başarılı dilsel güçlere sahip çeşitli şiir, hikâye, drama, günlükler, şarkı sözleri gibi alanları keşfetmelerini sağlar (Honig, 2017).

Bebekler ve yeni yürüyenlerin çıkardıkları seslere konuşma ve sözcükler ile karşılık vermek, ilk sözcükler için seslerle deneyimi özendirir. Çocuk ile birlikte dikkat etmek ve çocuğun gördükleri üzerinde konuşmak, erken dil başlangıcı ve kelime bilgisinin artmasını destekler. Bebek ve yeni yürüyenler ile oynanan şarkılı oyunlar, cee-e gibi oyunlar ise karşıllklı konuşmayı destekler (Berk, 2013a; Berk, 2013b). Çocuklar ile sohbet etme, sohbet sırasında yeni ve nadir kelimeleri kullanma ve açılama, taklit oyunu oynama, kitap okuma ve anlattırma dil gelişimini destekleyici etkinliklerdir (Bredekamp, 2015). Dil gelişimi sembolik oyun sırasında da desteklenmektedir. Bu oyunda yetişkin ve çocuklar işbirliği yaparak bir takım rollere girerler ve rolün gerektirdiklerini yaparlar. Çocukların dramatik oyun sırasında rollerine uygun şekilde konuşmaları dilin en gelişmiş formunu oluşturur. Çünkü çocuk oyunun senaryosuna göre dili plan yapmak, tahmin etmek, açıklamak, problem çözmek, tartışmak ve uzlaşmaya varmak, analiz etmek ve hiç maruz kalmadıkları durumları anlamak amacı ile kullanırlar (Weitzman ve Greenberg, 2012). Baron (1992), yetişkinlerin bebek ile konuşma başlatmasının ve onlara uyarım sağlamasının, yetişkinin konuştuklarını bebeğin anlıyormuş gibi davranmasının, yetişkinin kendini rahat hissettiği her türden bebek dilini kullanmasının, çocukların söylemeye çalş̧tıklarını sabırlı bir şekilde dinlemenin çocuğun dil gelişimini destekleyeceğini belirtmiştir (Akt. Santrock, 2016). Weitzman ve Greenberg (2012), bebeklerin dili öğrenmesine 
yardım etmek için yetişkinlerin kısa ve basit cümleler kullanmasını, bebeğin ilgi alanına göre cümleler kurmasını, bebeğin seslerine, mimiklerine ve hareketlerine uygun anlatmak istediğine uygun şekilde dil çıkarımları yapmasını, sosyal rutinlerinde bebeği cesaretlendirmeyi, bebeğin etrafinda olup bitenleri etiketlemeyi (burnunu silerken şimdi burnunu siliyorum demek gibi), bebeğin söylediklerini taklit etmeyi, çocuğun söylediklerinin açılımını yapmayı ve bir konu ile ilgili konuşurken konuyu genişletmeyi önermiştir. Bebekler ve çocuklar ile iletişim kurarken öğrenme dili kullanmak için, konuşmalar sırasında kelimelerin anlamlarını tanımlamak gerekir. Ayrıca konuşulan konu genişletilerek bebeğin bu konu hakkında daha çok şey öğrenmesi sağlanabilir. Bunlara ek olarak günlük hayatta yaşanan olaylardan, örneğin parmağınız sarılı ise parmağınıza ne olduğundan bahsederek, bir oyuncağın neden çalışmadığını, oyun hamurunun neden sert olduğunu anlatarak çocuklar ile bu konularda da konuşulması gerektiği belirtilmiştir (Weitzman ve Greenberg, 2012). Nash ve diğerlerine göre (2012) bebek ile birlikte bir şey yaparken yetişkinin yapılan işi isimlendirmesi, kelimeler ile anlatması, bebek ile iletişim kurarken yüz yüze olunması ve her gün bebek için önemli olan kelimeleri içeren kısa oyunlar oynanması dil gelişimini desteklemektedir. Finlandiya'da altı ile 24 aylık 508 bebek ve aileleri ile yapılan bir çalışmada, bebeklerin dil gelişimi uygun şekilde desteklenmediğinde ve dil gelissiminde gecikmeler yaşadıklarında, bu bebeklerin erken çocukluk dönemindeki öz düzenleme becerilerinin daha zayıf olduğu görülmüştür (Aro, Laakso, Maatta, Tolvanen ve Poikkeus, 2014).

\section{SONUÇ ve ÖNERİLER}

Dil gelişimi doğumdan başlayan, yeni yürüyen döneminde hızlı bir gelişim gösteren, tüm gelişim ve öğrenme sürecinin önemli bir parçasıdır. Yaşamın ilk yılını oluşturan dil gelişimi öncesi dönemde bebekler henüz ilk kelimelerini çıkarmadan bazı ses ve mimikleri kullanarak iletişim kurarlar. İki aydan sonra bebekler hoşnutluk sesleri (cıvıldama) çıkarmaya başlar, dört aydan sonra ise babıldama ve agulamalar başlar. Çocuğun dil gelişimi öncesi dönemdeki başarılı yetenekleri dil gelişimini inşa eden bloklardır. Seslerin ilk taklitleri ise on birinci ayda başlar, bir yaş civarında ise ilk kelimeler söylenmeye başlar. Bir ile bir buçuk yaşlar arası tek sözcük dönemi olarak isimlendirilmekte ve bu dönemde sözcük patlaması yaşanmaktadır. Bir buçuk iki yaşları arasında ise sözcüklerin ilişkisini anlamaya başlayarak iki sözcük dönemi görülür (Alhammadi, 2017; Macroy-Higgins ve Montemarano, 2016). Dolayısıyla yeni yürüyen dönemi dil gelişimi için kritik bir dönemdir. Bu dönemde çocuğun çevresindeki kişilerin dil gelişiminin özelliklerini bilmeleri ve çocukları uygun şekilde desteklemeleri gerekir. Alanyazın bilgileri ve yapılan çalışmalara göre dil edinimi ailenin, eğitimcilerin, toplumun, iletişim ve teknoloji araçlarının uyumu ile gerçekleşmektedir. Bu sebeple başta aile olmak üzere eğitimcilerin ve çocuğun yakın çevresinin duyarlı olması, uygun şekilde destek 
sağlaması gerekmektedir. Dil gelişimini desteklemede kullanılabilecek yöntemler ile ilgili yapılan çalışmalarda ve mevcut alan yazın bilgilerinde, kitap okumanın, resimli kitapları incelemenin, bebek ile sürekli etkileşim halinde olmanın ve oyun oynamanın, ortak dikkat geliştirmenin önemi ortaya konmuştur.

Yeni yürüyen döneminde alanyazında ve yapılan araştırmalarda dil gelişimini etkileyen hem biyolojik hem de çevresel birçok etken ortaya konmuştur. Bu etkenler arasında, beyin gelişimi, aile bireylerinin çocuk ile etkileşimi ve etkileşiminin kalitesi, ailenin sosyo-ekonomik düzeyi, öğrenim durumu, büyük kardeşe sahip olma, çocuğun cinsiyeti, erken doğum ve zamanında doğum yer almaktadır. Bu bağlamda, alan yazında yer alan dil gelişimi bilgileri ile son beş yılda yapılan araştırmaların birbirini desteklediği söylenebilir. Ancak Türkiye'de bu dönemde dil gelişimine ilişkin yapılan çalışmalar oldukça sınırlıdır. Gelecekte, dil gelişimi için duyarlı olunan yeni yürüyen döneminde, çocukların dil gelişimlerini daha belirgin ortaya koyacak, alanyazın bilgileri doğrultusunda derinlemesine yapılacak araştırmalara gereksinim vardır.

\section{KAYNAKÇA}

Aksoy, P. \& Baran, G. (2017) Dil gelişimi. Erken çocukluk döneminde gelişim I içinde. ( Ed. A. Köksal Aksoy) Ankara: Anı.

Aral, N. \& Doğan Keskin A. (2016). Bilişsel gelişim ve dil gelişimi. Çocuk gelişimi içinde. (Ed. N. Aral) Eskişehir: Anadolu Üniversitesi Açıköğretim Fakültesi

Bee, H. \& Boyd, B. (2009). Çocuk gelişimi psikolojisi. (O.Gündüz, Çev.) İstanbul: Kaknüs.

Berk, L. (2013a) Çocuk Gelişimi. (B.Onur \& A. Dönmez, Çev.) Ankara: İmge

Berk, L. (2013b) Bebekler ve Çocuklar. (N. Işıkoğlu, Çev.) Ankara: Nobel.

Bredekamp, S. (2015). Erken çocukluk eğitiminde etkili uygulamalar. (H. Z. İnan, T. İnan, Çev.). İstanbul :Nobel.

Çiçek, A. (2002). 0-6 yaş grubu çocuklarda dil gelişimi. Eræ̧incan Üniversitesi Eğitim Fakültesi Dergisi, 4(1).

Dağabakan, F. Ö., \& Dağabakan, D. (2007). Dil ve çocukta dil gelişim kuramları. Milli eğitim dergisi, 174(1), 8.

Karaslan, T., Beyazıt, U. \& Bütün Ayhan, A. (2015). Gelişimsel dönemler açısından hasta çocuklar ve hastane ortamının düzenlenmesi. Hasta Cocuklarnn gelişimi ve eğitimi içinde (Ed. A. Bütün Ayhan) Eskişehir: Anadolu Üniversitesi Açıköğretim Fakültesi

Karacan, E. (2000). Bebeklerde ve çocuklarda dil gelişimi. Klinik Psikizatri, 3(4), 263-268. 
McAfee, O. \& Leong, D.J. (2011). Erken çocukluk döneminde gelisim ve ögrenmenin değerlendirilmesi ve desteklenmesi. (Birsen Ekinci, Çev.). Ankara: Nobel.

Passer, M.W., \& Smith, R.E. (2008). Psychology: the science of mind and behavior. New York: McGrawHill.

Santrock, J.W. (2016). Yaşam boyu gelişim (G. Yüksel, Çev. Ed.) Ankara: Nobel.

Temizyürek, F. (2008). Çocukta dil gelişim süreci. Hacettepe Üniversitesi Türkiyat Araştırmalar (HÜTAD), (7), 169-176.

Trawick-Smith, J. (2017). Erken çocukluk döneminde gelişim. (B. Akman, Çev. Ed.). Ankara: Nobel.

Ünüvar, P. (2018). Bebeklik döneminde gelisim ve eğitim. Ankara : An1

Weitzman, E. \& Greenberg, J. (2012). Learning language and loving ıt. Toronto: The Hanen Centre Publication.

Yapıc1, Ş. (2004). Çocukta dil gelişimi. Journal of Human Sciences, 1(1).

Yazıc1, Z. (2018) 0-36 Aylık çocuklarda dil gelişimi. Bebeklik döneminde gelişim ve eğitim içinde. (Ed. P. Ünüvar) Ankara: An1.

\section{Ek 1. Araştırmada İncelenen Makale Listesi}

Adams, K. A., Marchman, V. A., Loi, E. C., Ashland, M. D., Fernald, A., \& Feldman, H. M. (2018). Caregiver talk and medical risk as predictors of language outcomes in full term and preterm toddlers. Child development, 89(5), 1674-1690.

Ahn, J., \& Yoo, J. P. (2016). The effect of infancy childcare center use and maternal employment on toddlers' language development in South Korea. Asian Social Work and Policy Review, 10(1), 130-141.

Alhammadi, F. S. (2017). Prediction of child language development: A review of literature in early childhood communication disorders. Lingua, 199, 27-35.

Aro, T., Laakso, M. L., Määttä, S., Tolvanen, A., \& Poikkeus, A. M. (2014). Associations between toddler-age communication and kindergarten-age self-regulatory skills. Journal of Speech, Language, and Hearing Research, 57(4), 1405-1417.

Austin, M. P., Christl, B., McMahon, C., Kildea, S., Reilly, N., Yin, C. \& King, S. (2017). Moderating effects of maternal emotional availability on language and cognitive development in toddlers of mothers exposed to a natural disaster in pregnancy: The QF2011 Queensland flood study. Infant behavior and development, 49, 296-309.

Bleses, D., \& Vach, W. \& Dale, P. S. (2018). Self-reported parental vocabulary input frequency for young children. Journal of child language, 45(5), 1073-1090.

Bridges, K., \& Hoff, E. (2014). Older sibling influences on the language environment and language development of toddlers in bilingual homes. Applied psycholinguistics, 35(2), 225-241. 
Brookes, I., \& Tayler, C. (2016). Effects of an evidence-based intervention on the Australian English language development of a vulnerable group of young Aboriginal children. Australasian Journal of Early Childhood, 41(4), 4-15.

Brósch-Fohraheim, N., Fuiko, R., Marschik, P. B., \& Resch, B. (2019). The influence of preterm birth on expressive vocabulary at the age of 36 to 41 months. Medicine, 98(6).

Cavalheiro, M. G., Lamônica, D. A. C., de Vasconsellos Hage, S. R., \& Maximino, L. P. (2019). Child development skills and language in toddlers with cleft lip and palate. International journal of pediatric otorbinolaryngology, 116, 18-21.

Conway, L. J., Levickis, P. A., Mensah, F., McKean, C., Smith, K., \& Reilly, S. (2017). Associations between expressive and receptive language and internalizing and externalizing behaviours in a community based prospective study of slow to talk toddlers. International journal of language communication disorders, 52(6), 839-853.

Dave, S., Mastergeorge, A. M., \& Olswang, L. B. (2018). Motherese, affect, and vocabulary development: dyadic communicative interactions in infants and toddlers. Journal of child language, 45(4), 917-938.

Gudmundsson, E. (2015). The Toddler Language and Motor Questionnaire: A mother-report measure of language and motor development. Research in developmental disabilities, 45, 21-31.

Güneş, F. (2015). Ninnilerin çocukların dil ve zihinsel gelişimine etkisi. Zeitschrift für die Welt der Türken/Journal of World of Turks, 2(3), 27-38.

Hawa, V. V., \& Spanoudis, G. (2014). Toddlers with delayed expressive language: An overview of the characteristics, risk factors and language outcomes. Research in developmental disabilities, 35(2), 400-407.

Honig, A. S. (2017). Language insights for caregivers with young children. Early Child Development and Care, 187(3-4), 527-541.

Hsu, N., Hadley, P. A., \& Rispoli, M. (2017). Diversity matters: Parent input predicts toddler verb production. Journal of child language, 44(1), 63-86.

Jensen, T. K., Mustieles, V., Bleses, D., Frederiksen, H., Trecca, F., Schoeters, G., \& Bilenberg, N. (2019). Prenatal bisphenol A exposure is associated with language development but not with ADHD-related behavior in toddlers from the Odense Child Cohort. Environmental research, 170, 398-405.

Justice, L. M., Jiang, H., Purtell, K. M., Schmeer, K., Boone, K., Bates, R., \& Salsberry, P. J. (2018). Conditions of poverty, parent-child interactions, and toddlers' early language skills in lowincome families. Maternal and child health journal, 1-8.

Lany, J. (2018). Lexical processing efficiency leverages novel word learning in infants and toddlers. Developmental science, 21(3), e12569.

Lee, B. Y. (2017). facilitating reading habits and creating peer culture in shared book reading: an exploratory case study in a toddler classroom. Early Childhood Education Journal, 45(4), 521 527. 
Loi, E. C., Vaca, K. E., Ashland, M. D., Marchman, V. A., Fernald, A., \& Feldman, H. M. (2017). Quality of caregiver-child play interactions with toddlers born preterm and full term: Antecedents and language outcome. Early buman development, 115, 110-117.

Lowe, J. R., Fuller, J. F., Do, B. T., Vohr, B. R., Das, A., Hintz, S. R., \& Human Development Neonatal Research Network. (2019). Behavioral problems are associated with cognitive and language scores in toddlers born extremely preterm. Early buman development, 128, 48-54.

Manz, P. H., Eisenberg, R., Gernhart, A., Faison, J., Laracy, S., Ridgard, T., \& Pinho, T. (2017). Engaging early head start parents in a collaborative inquiry: the co-construction of little talks. Early Child Development and Care, 187(8), 1311-1334.

Marchman, V. A., Adams, K. A., Loi, E. C., Fernald, A., \& Feldman, H. M. (2016). Early language processing efficiency predicts later receptive vocabulary outcomes in children born preterm. Child Neuropsychology, 22(6), 649-665.

Muluk, N. B., Bayoğlu, B., \& Anlar, B. (2016). A study of language development and affecting factors in children aged 5 to 27 months. ENT: Ear, Nose \& Throat Journal, 95(1).

Nash, M., Lowe, J. \& Leah, D. (2012). Supporting early language development. spirals for babies and toddlers. Oxon: Routledge.

Newman, R. S., Morini, G., Kozlovsky, P., \& Panza, S. (2018). Foreign accent and toddlers' word learning: the effect of phonological contrast. Language Learning and Development, 14(2), 97 112.

Nozadi, S. S., Spinrad, T. L., Eisenberg, N., Bolnick, R., Eggum-Wilkens, N. D., Smith, C. L., \& Sallquist, J. (2014). Prediction of toddlers' expressive language from maternal sensitivity and toddlers' anger expressions: A developmental perspective. Infant Behavior and Development, 36(4), 650-661.

Perry, L. K., \& Saffran, J. R. (2017). Is a pink cow still a cow? Individual differences in toddlers' vocabulary knowledge and lexical representations. Cognitive Science, 41(4), 1090-1105.

Potter, C. E., Fourakis, E., Morin-Lessard, E., Byers-Heinlein, K., \& Lew-Williams, C. (2019). Bilingual toddlers' comprehension of mixed sentences is asymmetrical across their two languages. Developmental science, 22(4).

Raby, K. L., Freedman, E., Yarger, H. A., Lind, T., \& Dozier, M. (2019). Enhancing the language development of toddlers in foster care by promoting foster parents' sensitivity: Results from a randomized controlled trial. Developmental Science, 22(2), e12753.

Roberts, M. Y., Curtis, P., Estabrook, R., Norton, E. S., Davis, M. M., Burns, J. \& Wakschlag, L. S. (2018). Talking tots and the terrible twos: early language and disruptive behavior in toddlers. Journal of Developmental \& Behavioral Pediatrics, 39(9), 709-714.

Rowe, M. L., Leech, K. A., \& Cabrera, N. (2017). Going beyond input quantity: Wh-questions matter for toddlers' language and cognitive development. Cognitive Science, 41, 162-179. 
Rujas, I., Casla, M., Mariscal, S., Lázaro López-Villaseñor, M., \& Murillo Sanz, E. (2019). Effects of grammatical category and morphology on fast mapping in typically developing and late talking toddlers. First Language, 0142723719828258.

Schwarz, A. L., Van Kleeck, A., Maguire, M. J., \& Abdi, H. (2017). Do acting out verbs with dolls and comparison learning between scenes boost toddlers' verb comprehension?. Journal of child language, 44(3), 719-733.

Stangeland, E., Lundetræ, K., \& Reikerås, E. (2018). Gender differences in toddlers’ language and participation in language activities in Norwegian ECEC institutions. European Early Childhood Education Research Journal, 26(3), 375-392.

Thurm, A., Manwaring, S. S., Cardozo Jimenez, C., Swineford, L., Farmer, C., Gallo, R., \& Maeda, M. (2018). Socioemotional and behavioral problems in toddlers with language delay. Infant mental health journal, 39(5), 569-580.

Umek, L., Peklaj, U., \& Socan, G. (2017). Early vocabulary, parental education, and the frequency of shared reading as predictors of toddler's vocabulary and grammar at age 2; 7 : a Slovenian longitudinal CDI study. Journal of child language, 44(2), 457-479.

Vauclair, J., \& Cochet, H. (2013). Hand preference for pointing and language development in toddlers. Developmental Psychobiology, 55(7), 757-765.

Yusuf, Q., Asyik, A. G., Yusuf, Y. Q., \& Rusdi, L. (2017). "Listen, do, repeat, understand and remember": Teaching English to very young children in Aceh. Iranian Journal of Language Teaching Research, 5(2), 113-132.

Zimmerman, F. J., Christakis, D. A., \& Meltzoff, A. N. (2007). Television and DVD/video viewing in children younger than 2 years. Archives of pediatrics \& adolescent medicine, 161(5), 473-479. 